\title{
Ice nucleation properties of fine ash particles from the Eyjafjallajökull eruption in April 2010
}

\author{
I. Steinke ${ }^{1}$, O. Möhler ${ }^{1}$, A. Kiselev ${ }^{1}$, M. Niemand ${ }^{1}$, H. Saathoff ${ }^{1}$, M. Schnaiter ${ }^{1}$, J. Skrotzki ${ }^{1}$, C. Hoose ${ }^{1}$, and \\ T. Leisner ${ }^{1,2}$ \\ ${ }^{1}$ Institute for Meteorology and Climate Research - Atmospheric Aerosol Research, Karlsruhe Institute of Technology, \\ Karlsruhe, Germany \\ ${ }^{2}$ Institute for Environmental Physics, Ruprecht-Karls-University Heidelberg, Heidelberg, Germany
}

Received: 9 May 2011 - Published in Atmos. Chem. Phys. Discuss.: 22 June 2011

Revised: 25 October 2011 - Accepted: 7 December 2011 - Published: 20 December 2011

\begin{abstract}
During the eruption of the Eyjafjallajökull volcano in the south of Iceland in April/May 2010, about $40 \mathrm{Tg}$ of ash mass were emitted into the atmosphere. It was unclear whether volcanic ash particles with $d<10 \mu \mathrm{m}$ facilitate the glaciation of clouds. Thus, ice nucleation properties of volcanic ash particles were investigated in AIDA (Aerosol Interaction and Dynamics in the Atmosphere) cloud chamber experiments simulating atmospherically relevant conditions. The ash sample that was used for our experiments had been collected at a distance of $58 \mathrm{~km}$ from the Eyjafjallajökull during the eruption period in April 2010. The temperature range covered by our ice nucleation experiments extended from 219 to $264 \mathrm{~K}$, and both ice nucleation via immersion freezing and deposition nucleation could be observed. Immersion freezing was first observed at $252 \mathrm{~K}$, whereas the deposition nucleation onset lay at $242 \mathrm{~K}$ and $\mathrm{RH}_{\text {ice }}=126 \%$. About $0.1 \%$ of the volcanic ash particles were active as immersion freezing nuclei at a temperature of $249 \mathrm{~K}$. For deposition nucleation, an ice fraction of $0.1 \%$ was observed at around $233 \mathrm{~K}$ and $\mathrm{RH}_{\text {ice }}=116 \%$. Taking ice-active surface site densities as a measure for the ice nucleation efficiency, volcanic ash particles are similarly efficient ice nuclei in immersion freezing mode $\left(n_{\mathrm{s}, \text { imm }} \sim 10^{9} \mathrm{~m}^{-2}\right.$ at $\left.247 \mathrm{~K}\right)$ compared to certain mineral dusts. For deposition nucleation, the observed ice-active surface site densities $n_{\mathrm{s} \text {,dep }}$ were found to be $10^{11} \mathrm{~m}^{-2}$ at $224 \mathrm{~K}$ and $\mathrm{RH}_{\text {ice }}=116 \%$. Thus, volcanic ash particles initiate deposition nucleation more efficiently than Asian and Saharan dust but appear to be poorer ice nuclei than ATD particles. Based on the experimental data, we have derived ice-active surface site densities as a function of temperature for immersion freezing and of relative humidity over ice and temperature for deposition nucleation.
\end{abstract}

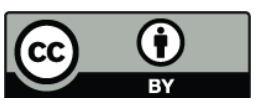

Correspondence to: I. Steinke (isabelle.steinke@kit.edu)

\section{Introduction}

Eruptions of volcanoes like El Chichon (1980) or Mt. Pinatubo (1991) had significant impacts on global atmospheric temperatures (Soden et al., 2002) because of the emission of large amounts of sulphur species into the stratosphere. Such major eruptions (with magnitudes larger than 4.5) occur at intervalls ranging from four years to about $1000 \mathrm{yr}$ depending on the eruption strength. Non-explosive volcanic activities involving slow degassing are associated with at least regional impacts on climate (Durant et al., 2010). For several years, attention to the impact of volcanic emissions on climate has been mainly focused on the contribution of volcanic sulphur species to the stratospheric aerosol layer and the subsequent impact on the global radiation budget (Mather et al., 2003) or, alternatively, the possible interaction between anthropogenic particles and sulphuric acid droplets of volcanic origin (Raga et al., 1999).

During the recent explosive eruption (April/May 2010) of the Eyjafjallajökull located on Iceland's southern coast, not only $3 \mathrm{Tg}$ of $\mathrm{SO}_{2}$ were released into the atmosphere, but also about $10 \mathrm{Tg}$ of distal ash mass (Schumann et al., 2011). Estimates from inverse modelling suggest that volcanic ash emissions with regard to particles with diameters between 2.8 and $28 \mu \mathrm{m}$ amount to approximately $8 \mathrm{Tg}$ (Stohl et al., 2011). The Eyjafjallajökull eruptions in 2010 generally reached heights of several kilometres producing an ash cloud which was transported over a distance of several hundreds of kilometres (Gudmundsson et al., 2010). The spreading of the volcanic plume was observed by in-situ measurements, ceilometers, lidars, sun photometers and ozone sondes - volcanic ash was transported towards Northern and North Western Europe, where the arrival of the plume in Southern Germany was accompanied by simultaneous increases in concentrations of $\mathrm{SO}_{2}$ and particles larger than $1 \mu \mathrm{m}$ (Flentje et al., 2010).

Published by Copernicus Publications on behalf of the European Geosciences Union. 
Because of their higher settling velocities, the largest particles within the volcanic plume are rapidly lost due to sedimentation during atmospheric transport, whereas ash particles smaller than $\sim 10 \mu \mathrm{m}$ may stay elevated at higher altitudes for a longer period of time. These small ash particles are predicted to have atmospheric residence times of several days (Rose and Durant, 2009). This prediction is supported by atmospheric measurements within the volcanic plume where it was found that within two to three days the number concentration of particles larger than $\sim 2 \mu \mathrm{m}$ is further decreased due to sedimentation (Schumann et al., 2011).

These small ash particles remaining in the troposphere may alter cloud properties by acting as ice nuclei in mixedphase and cirrus clouds. Since heterogeneous ice nucleation has been identified as a very important process with regard to impact on precipitation and the atmospheric radiation budget, the need to better characterise ice nucleation properties of atmospheric particles has arisen. Heterogeneous ice nucleation is initiated by the presence of typically insoluble particles leading to a reduction of the Gibbs free energy for the formation of a critical ice germ - these particles are called ice nuclei (IN) (Pruppacher and Klett, 1997; Cantrell and Heymsfield, 2005). Ice nucleation can occur as immersion/condensation freezing, deposition nucleation or contact freezing (Vali, 1985). Immersion freezing requires the presence of an undissolved aerosol particle within the supercooled liquid droplet for freezing to be initiated. In the case of condensation freezing, condensation of water onto the aerosol particle precedes the freezing of the liquid droplet. Deposition nucleation, in contrast, refers to the direct transformation of water vapour into ice at the particle surface. Freezing via contact nucleation is caused by the collision between an aerosol particle and a supercooled liquid droplet (Cooper, 1974; Shaw et al., 2005).

In laboratory experiments (Durant et al., 2008; Fornea et al., 2009 and references therein) and atmospheric measurements (Bingemer et al., 2011; Seifert et al., 2011) the role of volcanic ash particles as potential ice nuclei has been investigated.

Volcanic ash particles $(250<d<300 \mu \mathrm{m})$ from Mt. St. Helens were observed to nucleate ice via immersion freezing at temperatures of about $255 \mathrm{~K}$ (Fornea et al., 2009). For several Japanese volcanoes such as Mt. Asama, a significant correlation between volcanic activity and the increase of atmospheric ice nuclei concentrations in Tokyo was observed for meteorological conditions which allowed the transport of volcanic ash over several kilometres. The increase in IN concentrations was especially pronounced for temperatures below $258 \mathrm{~K}$ (Isono et al., 1959a). A similar observation was made for Hawaiian volcanoes, where eruptions of the Kilauea were followed by IN concentrations (measured at $252 \mathrm{~K}$ ) rising to more than one order of magnitude above background concentrations (Hobbs et al., 1971).
Even though it was demonstrated that volcanic ash particles can be efficient ice nuclei, it remained unclear whether volcanic ash particles are relevant for atmospheric ice nucleation processes, since the ash particles' properties as iceforming nuclei had neither been investigated for particles smaller than $\sim 100 \mu \mathrm{m}$ nor for temperatures below $\sim 250 \mathrm{~K}$. Also, some measurements suggest that not all eruptions contribute to atmospheric IN concentrations, as the icenucleation properties of volcanic ash particles depend on their volcanic source and the resulting chemical composition (Isono et al., 1959a) - e.g. volcanic ash particles might become deactivated in volcanic plumes which are rich in sulphuric gases (Schnell and Delany, 1976). A comparison of ash samples from ten different Japanese volcanoes indeed has shown that freezing thresholds vary not only amongst volcanoes, but also for different types of eruptions. In general, however, freezing onset temperatures varied between 250 and $265 \mathrm{~K}$ (Isono et al., 1959b). This range of freezing onset temperatures agrees with studies that have investigated the ice nucleation properties of volcanic ash from Mt. Etna (Italy), Crater Lake (USA) and Pericuten (Mexico). For all these samples ice nucleation was initiated at temperatures between 257 K and 265 K (Mason and Maybank, 1958; Schaefer, 1949). Single-particle measurements with two different types of volcanic ash (trachandesitic and balsaltic reticulite) found that freezing was initiated at temperatures between 250 and $255 \mathrm{~K}$ for both types of ash (Durant et al., 2008).

This paper presents laboratory results from cloud chamber experiments with volcanic ash from the Eyjafjallajökull eruption in April 2010. Since our experiments were conducted over a temperature range between 219 and $264 \mathrm{~K}$, our results are relevant for ice nucleation processes in mixed-phase and cirrus clouds. In this work a detailed characterisation of the ice nucleation properties of volcanic ash particles is presented together with aspects related to particle morphology and composition. For the evaluation of the ice nucleation efficiency of the volcanic ash particles, the concept of the socalled ice-active surface site density was employed (DeMott, 1995; Connolly et al., 2009; Niedermeier et al., 2010; Niemand et al., 2011). It relies on the assumption that ice-active sites at the surface of the aerosol particles initiate ice nucleation at a certain temperature and relative humidity over ice (Fletcher, 1969; Vali, 1971).

\section{Experimental methods}

All measurements presented in this paper were conducted at the AIDA (Aerosol Interaction and Dynamics in the Atmosphere) aerosol and cloud chamber facility at the Karlsruhe Institute of Technology. Within the AIDA chamber humidified air can be expanded and thereby cooled, simulating the ascent of an air parcel in the atmosphere. This experimental setup makes it possible to investigate atmospheric ice nucleation processes. Rigorous cleaning (i.e. pumping the vessel 


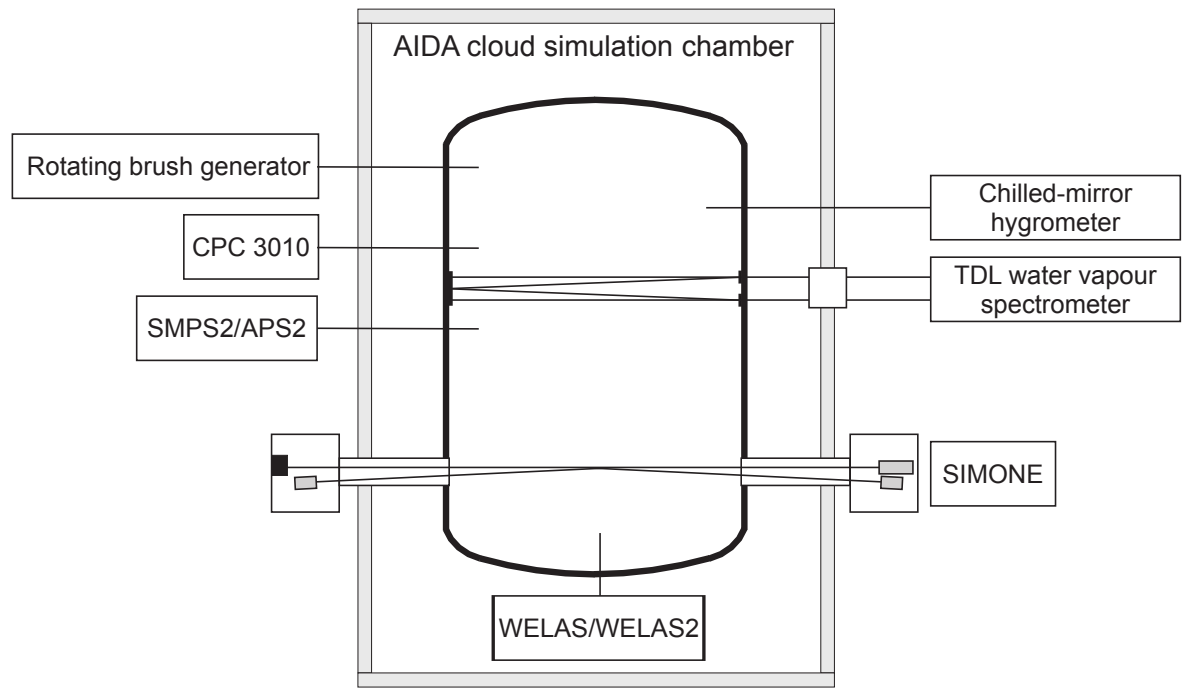

Fig. 1. Schematic drawing of the AIDA cloud chamber: aerosol instrumentation (rotating brush generator, APS, SMPS, CPC3010) and instruments used for characterisation of the droplet/ice crystal population (WELAS/WELAS2, SIMONE) and relative humidity measurements (TDL, chilled-mirror hygrometer).

down to pressures below $0.1 \mathrm{hPa}$ and flushing with synthetic air) results in very low background concentrations of aerosol particles (typically below $0.1 \mathrm{~cm}^{-3}$ ). Additionally, most expansion experiments were preceded by a reference activation during which the background aerosol is activated to droplets or ice crystals, depending on the temperature and humidity conditions within the chamber. With this procedure an almost complete removal of background particles from the cloud chamber system is achieved.

Figure 1 shows a schematic drawing of the AIDA chamber: the vessel, where the experiments take place, is situated within a large temperature-controlled housing. For the expansion experiments, the gas pressure inside the vessel is lowered at controllable rates with a strong vacuum pump. The experiments presented in this paper were conducted within a temperature range between 219 and $264 \mathrm{~K}$. With several optical instruments, aerosol particles, droplets and ice crystals can be measured and distinguished from each other. In the following, the characteristics of these instruments (Wagner et al., 2009) will be summarised briefly:

- Sizing and counting of the droplet and ice crystal population is done by the two optical particle counters $W E$ $L A S$ and WELAS2 (Palas $\mathrm{GmbH}$ ) which detect scattering signals from single particles crossing a beam of white light within the respective instrument. The intensity of the scattering pulses is then taken as a measure of the corresponding particle size. The detection ranges (for liquid droplets) are $0.7-40 \mu \mathrm{m}$ and $2.3-104 \mu \mathrm{m}$, respectively. The differentiation between ice crystals and water droplets is made according to the fact that typically ice crystal sizes exceed those of water droplets. Therefore, a size threshold can be set which allows to calculate the number concentration of ice crystals and later on the fraction of ice crystals with respect to the total aerosol number concentrations as measured by a condensation particle counter (CPC3010, TSI).

- SIMONE (Scattering Intensity Measurements for the Optical Detection of Ice) detects scattering signals from particles crossing the pathway of a laser beam $(\lambda=$ $488 \mathrm{~nm}$ ) which horizontally traverses the cloud chamber. Scattering signals are measured in forward (at $2^{\circ}$ ) and near-backward (at $178^{\circ}$ ) direction. Additionally, for the near-backward scattering signal, the depolarisation, which can be taken as an indicator of the dominating presence of either water droplets or ice crystals, is measured using a Glan laser prism to separate the parallel and the perpendicular polarized components of the nearbackward scattered light.

- The humidity conditions in the cloud chamber are derived from $T D L$ (tunable diode laser) absorption spectroscopy measurements. From scanning over a selected water-vapour absorption line at $1.37 \mu \mathrm{m}$, the absolute concentration of water vapour within the cloud chamber can be inferred with an accuracy of $\pm 5 \%$. The concentration measurements can then be converted into relative humidity using the AIDA mean gas temperature $T_{\mathrm{g}}$ and the saturation vapour pressure of water (Murphy and Koop, 2005). Additionally, the total water concentration can be determined from chilled mirror hygrometer measurements and used to calculate the condensed water content.

With this instrumentation, ice nucleation via immersion freezing can be clearly distinguished from deposition 
nucleation. In Fig. 2 data for two experiments is shown - the experiment on the left (1a to 1e) is an example for immersion freezing of volcanic ash (EY01), whereas the experiment on the right side (2a to $2 \mathrm{e}$ ) is characterised by pure deposition nucleation.

As the structure of the data sets is conceptually the same for both experiments, a general overview will be given, together with the main conclusions that can be drawn from the measurements:

- The first panels (a) show the progression of an expansion experiment: the cloud chamber is pumped down from atmospheric pressure to a pressure $p$ of $\sim 800 \mathrm{hPa}$. At the same time, the gas temperature $T_{\mathrm{g}}$, which is the average temperature in the volume of the cloud chamber, drops. The temperature $T_{\mathrm{w}}$, which is the average of several sensors on the walls of the aerosol vessel, remains almost constant during the expansion.

- Panels (b) show the evolution of the relative humidities over water $\left(\mathrm{RH}_{\mathrm{wat}}\right)$ and over ice $\left(\mathrm{RH}_{\mathrm{ice}}\right)$ as derived from the TDL water vapour measurements.

- The SIMONE depolarisation signal is shown in panels (c): in our experiments, a depolarisation value of $\sim 0.3$ was observed for the volcanic ash particles. The growth of droplets and ice crystals can be clearly differentiated: formation of (spherical) droplets is accompanied by a decrease in depolarisation. Low number concentrations of nonspherical ice crystals, in contrast, do not lead to an overall change in depolarisation.

- The particle concentrations and size distributions that are shown in the panels (d) and (e) are compilations of data from WELAS, WELAS2 and CPC3010. The WELAS and WELAS2 instruments give information regarding the number concentrations (panels d) and optical sizes (panels e) of droplets and ice crystals. The particles measured by WELAS/WELAS2 before the expansion experiment starts are aerosol particles that are large enough to be detected by these instruments. In panel d), the number concentration as measured by the two optical particle counters is shown without differentiating between aerosol particles, droplets and ice crystals (Welas all). Additionally, the ice crystal concentration can be derived by applying a size threshold to the data presented in panels (e) according to the fact that ice crystals are much larger than aerosol particles and droplets. For the immersion freezing experiment, the separation between droplet population and ice crystals is clearly visible (1e). Thus, the threshold is set at a particle size of $d=20 \mu \mathrm{m}$. For deposition nucleation, this ice crystal threshold is more difficult to find and set to a slightly smaller value of $d=15 \mu \mathrm{m}$ in order not to underestimate the number density of small ice crystals. Complementing the data on droplets and ice crystals, the aerosol particle concentration is shown in panels (d).
Putting together the information from all the instruments, it is possible to distinguish between immersion freezing (1a to 1e) and deposition nucleation ( $2 \mathrm{a}$ to $2 \mathrm{e}$ ): First, from looking at the humidity data $(1 b$ and $2 b)$ it can be seen that water saturation is only reached during the first experiment. The emergence of droplets is confirmed by the decrease of the depolarisation signal (1c) from $\sim 0.3$ to values below 0.05 - this can be reasoned by the fact that aerosols which have been activated to droplets, in contrast to dry aerosol particles, are spherical objects which do not cause significant depolarisation. For deposition nucleation, the depolarisation signal (2c) is more difficult to interpret because it also depends on ice crystal sizes and habits: during our experiments, overall, a slight decrease in depolarisation was observed during deposition nucleation. Sometimes, however, the initiation of deposition nucleation can be accompanied by an increase in depolarisation (2e) which can be explained by the presence of small micrometer-sized ice particles during the initial nucleation and growth stage as such small particles have a maximum in depolarisation (Wagner et al., 2009).

Another feature which differs between immersion freezing and deposition nucleation is the temporal development of the ice crystal population. For immersion freezing, droplet concentrations converge towards the aerosol number concentration (1d) upon reaching water saturation: this results from of the activation of aerosol particles to droplets which allows small aerosol particles to grow into the detection range of the WELAS instrument. In the range between 1 and $10 \mu \mathrm{m}$, a dense droplet cloud is detected by the WELAS instrument before ice nucleation is initiated. The WELAS2 instrument (blue dots) only detects the largest droplets (1e). Since within our measurement uncertainty all volcanic ash particles are activated to droplets (leaving no dry aerosol particles available), it is unlikely for contact nucleation to occur during the AIDA experiments presented in this study. For deposition nucleation, the number of particles as detected by WELAS is lower than the aerosol concentration throughout the experiment (2d). Also, there is no droplet formation prior to ice nucleation (2e), but reaching a certain supersaturation over ice is followed by rapid growth of ice crystals into the WELAS/WELAS2 detection ranges (2e). Immersion freezing is accompanied by the emergence of droplets when reaching saturation over water, which can be recognised from the large decrease in depolarisation (1c). Ice nucleation sets in only after droplet formation has started $(1 \mathrm{~d}, 1 \mathrm{e})$. In contrast, deposition nucleation is associated with an immediate growth of ice crystals at a certain supersaturation over ice (2d, 2e), which then leads to a significant temporary increase in depolarization while for immersion freezing and low ice crystal concentrations the depolarization is not influenced much by ice nucleation and ice crystal growth over the course of the experiment.

The volcanic ash sample (referred to as "EY01") that we used had been collected at a distance of $58 \mathrm{~km}$ from the Eyjafjallajökull on the morning of 15 April 2010 af- 

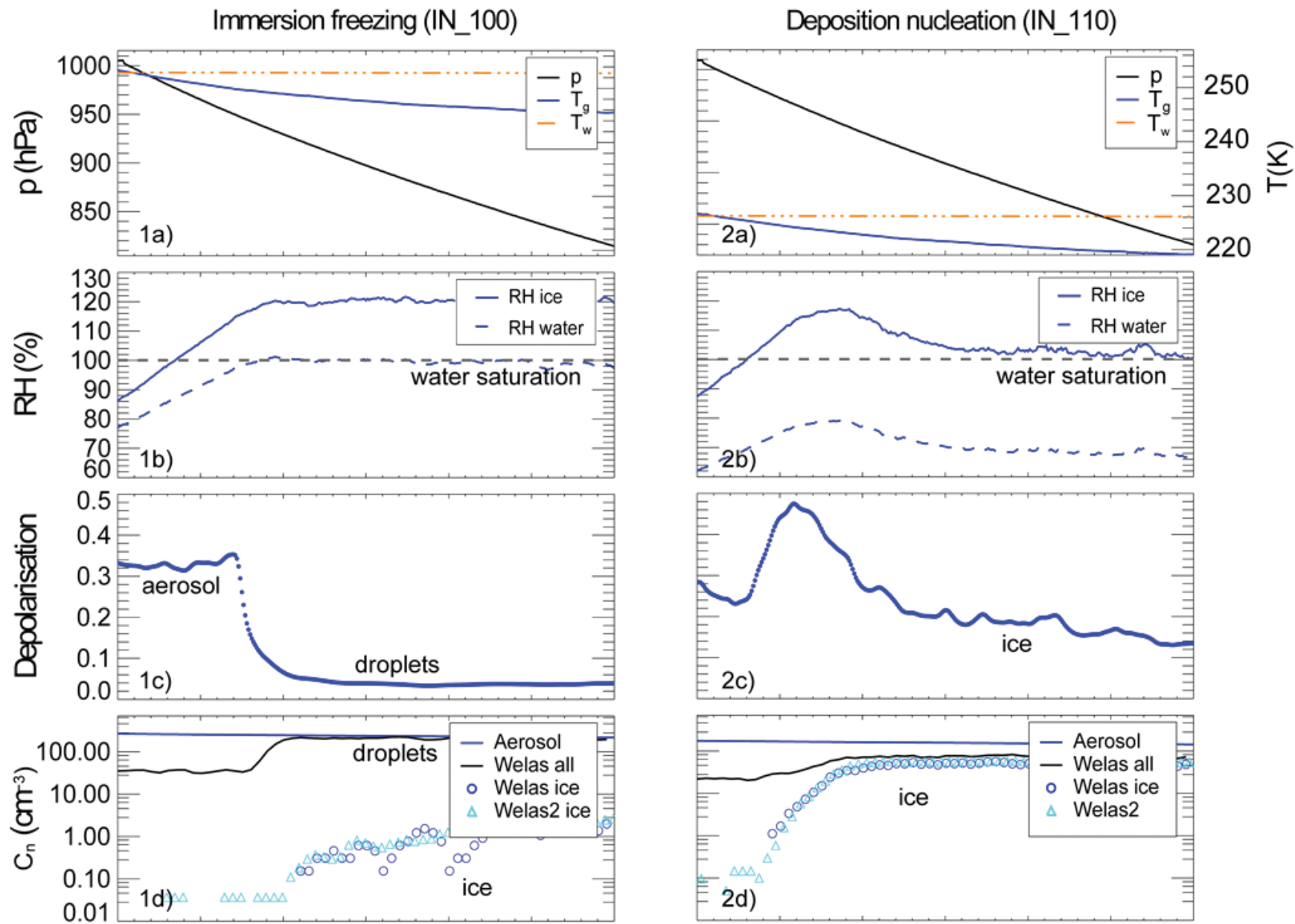

220
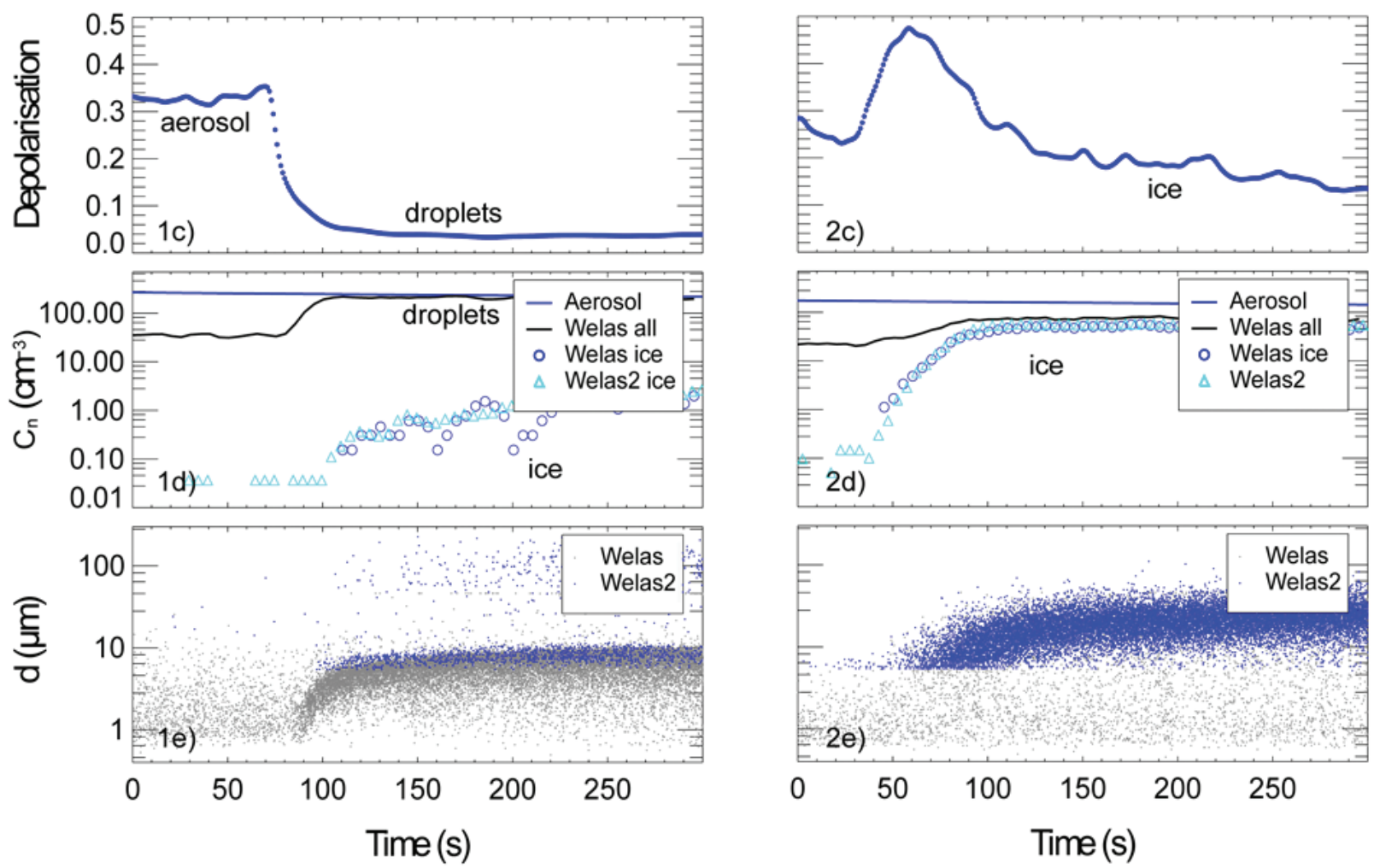

Fig. 2. Time series of two experiments showing immersion freezing (1a-1e) and deposition nucleation (2a-2e). (a) Variation of the thermodynamical variables during expansion: decrease in gas temperature $T_{\mathrm{g}}$ and pressure $p$; temperature at the walls of the vessel $T_{\mathrm{W}}$ stays approximately constant, (b) Development of relative humidity over water and over ice as derived from TDL data, (c) Depolarisation of the backwardly scattered light (SIMONE) as an indication for the dominance of either droplets or ice crystals, (d) Aerosol number concentrations (CPC3010) compared to particle concentrations (WELAS/WELAS2); ice crystal number concentrations are calculated from WELAS/WELAS2 data, (e) Temporal evolution of particle sizes as measured by WELAS/WELAS2

ter a major eruption phase had started on 13 April 2010 (Gudmundsson et al., 2010). According to a study by Gislason et al. (2011), the ash from Eyjafjallajökull is dominated by andesitic glass. However, they also found crystals of plagioclase, pyroxene and olivine. Further details with regard to the circumstances of this volcanic eruption and their influence on the properties of the volcanic ash particles can be found in Hoyle et al. (2011). Note that for phase II of the eruption (14-17 April 2010) it is assumed that aggregation in the water-rich plume enhanced the sedimentation of the small particles (Ilyinskaya et al., 2011). These particle agglomerates can be (at least partially) broken up when the 
Table 1. Overview of ice nucleation experiments with EY01 as carried out at the AIDA cloud chamber; reference experiments being omitted

\begin{tabular}{lllllll}
\hline Experiment & $\begin{array}{l}T_{\text {start }} \\
(\mathrm{K})\end{array}$ & $\begin{array}{l}T_{\text {min }} \\
(\mathrm{K})\end{array}$ & $\begin{array}{l}\text { Particles } \\
\text { with } d>5 \mu \mathrm{m} \\
\text { included? }\end{array}$ & $\begin{array}{l}\text { Aerosol surface } \\
\text { area density } \\
\left(\mu \mathrm{m}^{2} \mathrm{~cm}^{-3}\right)\end{array}$ & $\begin{array}{l}\text { Droplet } \\
\text { activation } \\
\text { observed? }\end{array}$ & $\begin{array}{l}\text { Ice } \\
\text { nucleation? }\end{array}$ \\
\hline IN14_95 & 264 & 257 & yes & 459 & yes & no \\
IN14_98 & 259 & 252 & yes & 481 & yes & immersion freezing \\
IN14_100 & 253 & 245 & yes & 385 & yes & immersion freezing \\
IN14_103 & 253 & 244 & no & 400 & yes & immersion freezing \\
IN14_105 & 245 & 238 & no & 461 & yes & imm. freezing/dep. nucleation \\
IN14_107 & 236 & 229 & no & 237 & no & no \\
IN14_110 & 226 & 219 & no & 157 & & deposition nucleation \\
\end{tabular}

aerosol is drily dispersed as in our experiments, which sets free the smaller, atmospherically relevant particles.

The sample was introduced into the AIDA chamber with a rotating brush generator (RBG 1000, Palas) and later on characterised with SMPS (Scanning Mobility Particle Sizer - TSI) and APS (Aerodynamical Particle Sizer - TSI) measurements delivering a size distribution of the aerosol particles. From the aerosol number size distribution that is obtained by combining the APS and SMPS data (Möhler et al., 2008), the aerosol surface distribution can be estimated - assuming that the aerosol particles are spherical - and subjected to a lognormal fitting routine. Filter samples were taken from the aerosol in the cloud chamber and analysed with an environmental scanning electron microscope (ESEM - FEI Quanta 650 FEG) combined with an energy dispersive X-ray analysis module (EDX - QUANTAX, Bruker). This method gives access to the surface morphology and the chemical composition of individual particles. Additionally, the amount of soluble sulphates on the surfaces of the ash particles was analysed with an ion chromatograph (DX500, Dionex): for this analysis $53 \mathrm{mg}$ of volcanic ash were suspended in $20 \mathrm{ml}$ of high-purity water (Nanopure, Barnstead) and only the solution was analysed for major anions and cations including sulphate.

An overview of all relevant experiments with the EY01 sample is given in Table 1 as a reference for experiments mentioned in the following section in which the results are presented. Note that reference experiments, in which the background aerosol in the cloud chamber was activated, are not listed. $T_{\text {start }}$ denotes the temperature at the beginning of the respective expansion experiment, whereas $T_{\min }$ is the lowest temperature reached during the experiment.

\section{Results}

In the following sections we will first present our results on the ash particle surface distributions, morphology, and chemical composition. The second section will deal with the threshold conditions for different ice-active particle fractions. The third part is dedicated to the relation between ice-active surface site densities and temperature for immersion freezing and, accordingly, the relation between iceactive surface site densities and the two variables temperature and supersaturation over ice for deposition ice nucleation.

\subsection{Characteristics of volcanic ash particles: aerosol surface distribution and morphology}

From the combination of APS and SMPS measurements, the surface distribution of the volcanic ash particles in the AIDA chamber can be derived: one of these surface distributions is shown in Fig. 3a. The aerosol surface distributions are calculated from the APS and SMPS number size distributions as described by Möhler et al. (2008). For calculating the aerosol surface distribution of the ice-inducing volcanic ash particles, a unimodal lognormal size distribution was fitted to the measured data. For this fit, the density was estimated to be $2.6 \mathrm{~g} \mathrm{~cm}^{-3}$, assuming that volcanic ash has a similar density compared to mineral dusts also consisting mainly of silicates. Volcanic ash particles smaller than $0.1 \mu \mathrm{m}$ do not significantly contribute to the aerosol surface distribution. The fitted aerosol surface mode includes particles with diameters between 0.1 and $15 \mu \mathrm{m}$ for exp. IN_100 (resp. $5 \mu \mathrm{m}$ for exp. IN_103), with a median diameter of $\sim 0.4 \mu \mathrm{m}$ and a standard deviation of $\sigma=1.8$ (number size distributions not shown). For investigating the relative contribution of larger particles $(d>5 \mu \mathrm{m})$ to the ice nucleation efficiency of the total volcanic ash particle population, two ice nucleation experiments (IN_100 and IN_103) were conducted at the same temperature, but with different aerosol size cutoffs. As can be seen from Fig. 3, this cutoff lies at $\sim 15 \mu \mathrm{m}$ for experiment IN_100, and at $\sim 5 \mu \mathrm{m}$ for experiment IN_103. In the first case, particles larger than $\sim 15 \mu \mathrm{m}$ are eliminated since the dispersion of the aerosol is accompanied by losses within the tubes that lead from the rotating brush generator to the cloud chamber aerosol inlet.

For experiment IN_103, an impactor stage (cyclone 3) was used with the rotating brush generator which led to a discrimination of particles larger than $\sim 5 \mu \mathrm{m}$. This discrimination is reflected in the corresponding surface distribution which is shown in Fig. 3b. The median of the aerosol surface 
a)

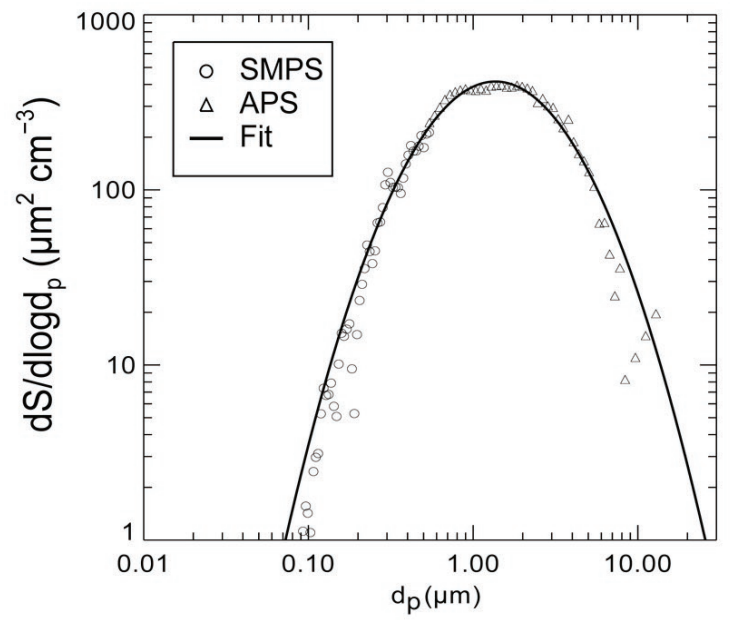

b) with impactor stage (cyclone 3)

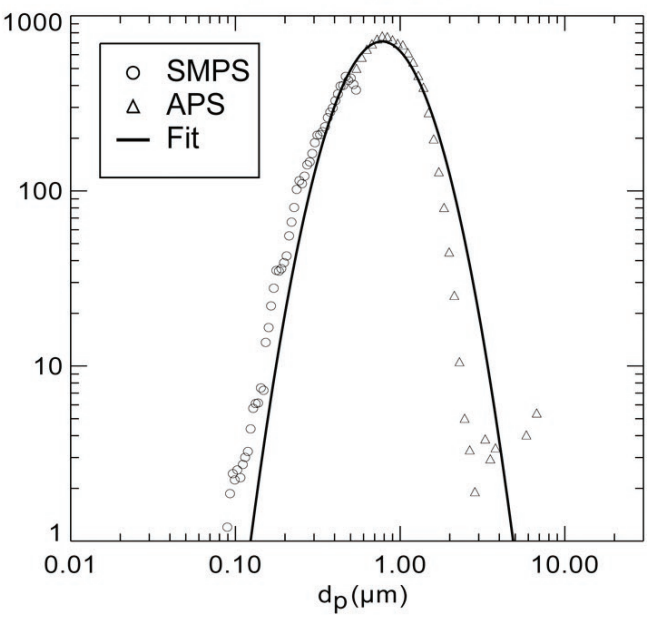

Fig. 3. Aerosol surface distributions of volcanic ash particles: comparison between distributions as obtained without (a) and with (b) using an impactor (cyclone 3) - aerosol surface distributions are calculated from number size distributions as measured by APS and SMPS (a) $d_{\text {med,surf }}=1.36 \mu \mathrm{m} ; \sigma_{\text {surf }}=2.33\left(\right.$ exp. IN14_100) (b) $d_{\text {med,surf }}=0.77 \mu \mathrm{m} ; \sigma_{\text {surf }}=1.66(\exp$. IN14_103)

distribution is shifted from $d_{\text {med,surf }}=1.36 \mu \mathrm{m}$ to a smaller value $d_{\text {med,surf }}=0.77 \mu \mathrm{m}$ when using a cyclone. The use of an impactor stage also influences the width of the aerosol surface distributions as indicated by the standard deviation decreasing from $\sigma_{\text {surf }}=2.33$ to $\sigma_{\text {surf }}=1.66$. From the aerosol surface distributions it can be seen that the volcanic ash particles used in our experiments fall mostly within the atmospherically relevant size range of particles smaller than $\sim 10 \mu \mathrm{m}$ which can stay elevated for several days (Rose and Durant, 2009).

In Fig. 4 two ESEM images of volcanic ash particles are shown. The particle on the left side of Fig. 4 has relatively sharp edges with smaller particles being attached to the particle's surface. The picture on the right side shows a particle that consists of several small particles (with sizes of $\sim 0.2 \mu \mathrm{m}$ ). For an ensemble of 7 particles, a more detailed analysis was conducted: the surface characteristics of these volcanic ash particles are similar to those that have been observed in atmospheric measurements (Schumann et al., 2011). However, we did not observe particles consisting solely of sulphates. The most abundant components found in our EDX analysis are silicates alongside with aluminium oxide, which is in agreement with atmospheric measurements finding that particles larger than $0.5 \mu \mathrm{m}$ consisted mainly of silicates (Schumann et al., 2011). The high silicate content suggests that volcanic ash particles are on average chemically akin to particles belonging to the coarse fraction of certain mineral dusts (e.g. Saharan dust) (Formenti et al., 2003; Linke et al., 2006; Krueger et al., 2004). Compared to mineral dusts, volcanic ash particles may have been exposed to additional chemical processing because of the presence of sulphuric acid during particle production (Mather et al.,
2003). Therefore we have also measured the sulphate content in our volcanic ash samples by ion chromatography. The sulphate content as derived from our leaching experiments was approximately $0.1 \mathrm{~g}$ per $\mathrm{kg}$ of ash mass, which is slightly lower than for similar samples that have been investigated (Eiríksdottir and Alfredsson, 2010). However, direct atmospheric measurements of volcanic ash particles being coated by sulphuric acid are still missing (Flentje et al., 2010).

\subsection{Ice nucleation threshold conditions in immersion freezing and deposition nucleation mode}

Figure 5 shows the ice nucleation threshold conditions for certain ice fractions $f$. Ice fractions $f$ refer to the ratio between number densities of ice crystals and the total aerosol number concentration. For comparison, freezing threshold measurements for Asian and Saharan dust (Field et al., 2006) are included in Fig. 5.

Note that the relative humidities over liquid water and over ice $\left(\mathrm{RH}_{\text {wat }}, \mathrm{RH}_{\text {ice }}\right)$ - as calculated from the measured water vapour concentration and the mean gas temperature - have been corrected in order to match the relative humidities at droplet activation with the state of water saturation at which droplet activation occurs. The underestimation of $\mathrm{RH}_{\text {wat }}$ ranged from 4 to $7 \%$ for temperatures above $245 \mathrm{~K}$. There are several reasons which might serve as an explanation for this systematic deviation: possible temperature measurement errors due to condensation of water vapour on the temperature sensors at high temperatures cannot be excluded and can negatively impact the retrieval of $\mathrm{RH}_{\mathrm{wat}}$. The underestimation of $\mathrm{RH}_{\text {wat }}$ might also be caused by inhomogeneities in particular close to the walls of the cloud chamber - leading to a lower average humidity in the chamber than in the 

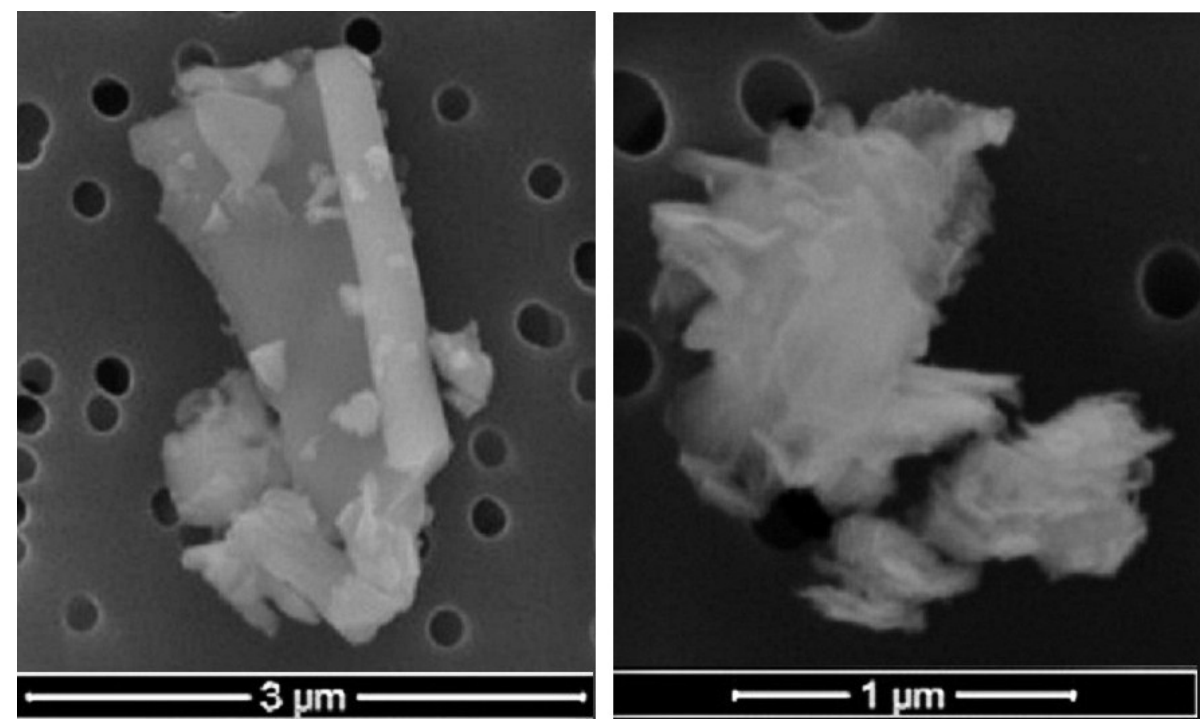

Fig. 4. ESEM images of two ash particles from the Eyjafjallajökull (sample name: EY01): examples for different particle surface structures.

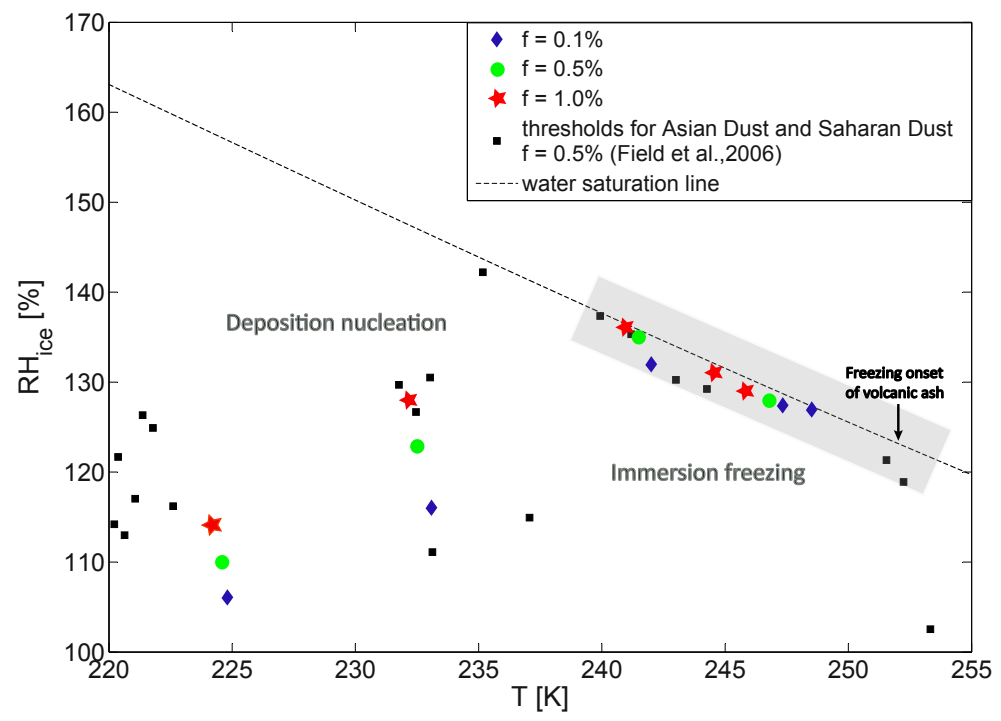

Fig. 5. Immersion freezing at water saturation and deposition nucleation: ice nucleation threshold conditions for different ice fractions $f$ $(\bullet, \bullet, \star)$ produced by volcanic ash (EY01) compared to cloud chamber experiments (Field et al., 2006) with Saharan and Asian Dust (ם) the shaded area illustrates the measurement uncertainty of $\mathrm{RH}_{\text {ice }}$ at water saturation.

regions of droplet activation. The relative humidity over ice $\left(\mathrm{RH}_{\text {ice }}\right)$ is measured with an uncertainty of $\pm 3-5 \%$ (Fahey et al., 2009).

There are two distinct groups of ice nucleation thresholds (Fig. 5): immersion freezing after droplet activation occurs at water saturation for temperatures above $240 \mathrm{~K}$. At lower temperatures, only deposition nucleation is observed in our experiments. Immersion freezing was first observed at a temperature of $252 \mathrm{~K}$. However, at this temperature the ice fractions did not exceed $0.1 \%$. For immersion freezing the highest observed ice fraction amounts to $f=2 \%$ at $245 \mathrm{~K}$, whereas for deposition nucleation the maximum ice fraction observed is $f=40 \%$ at $\mathrm{RH}_{\text {ice }}=117 \%$ and a temperature of $223 \mathrm{~K}$. Our measurements compare very well with ice nucleation thresholds observed during ice nucleation experiments with Asian and Saharan dust as similar maximum ice fractions of $\sim 45 \%$ were observed for both mineral dusts at temperatures below $233 \mathrm{~K}$ (Field et al., 2006). However, for Saharan dust (Field et al., 2006), freezing was observed close to water saturation at comparatively low temperatures $(\sim 235 \mathrm{~K})$ where deposition nucleation was dominant for the volcanic ash particles. For single droplet experiments with 


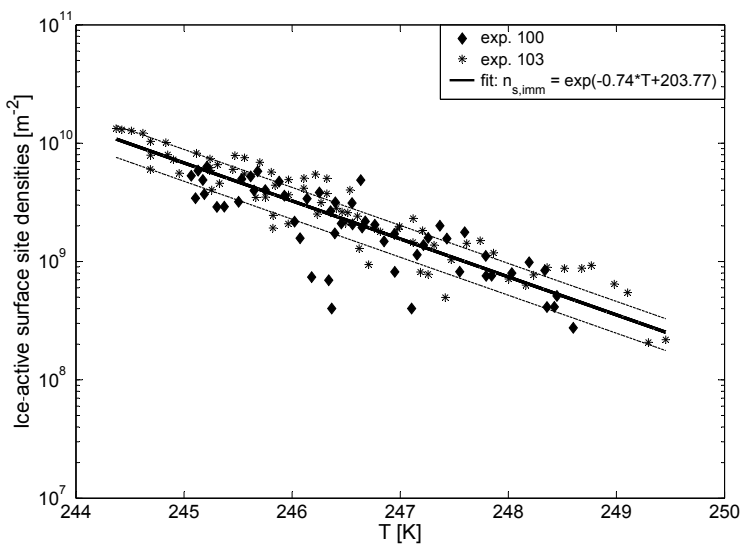

Fig. 6. Ice-active surface site densities for immersion freezing of volcanic ash particles (EY01) with fit (-) and measurement uncertainties (- -).

volcanic ash particles, the onset of freezing was observed at temperatures between 250 and $260 \mathrm{~K}$ (Durant et al., 2008; Fornea et al., 2009) where ice fractions where below $0.1 \%$ in our experiments for volcanic ash (EY01). However, this might be due to the comparably large size $(>100 \mu \mathrm{m})$ of the particles which where used in the studies conducted by $\mathrm{Du}-$ rant et al. (2008) and Fornea et al. (2009). These large particles can be assumed to have increased freezing probabilities at higher temperatures due to the larger available ice nucleus surface.

\subsection{Ice-active surface site densities for immersion freezing and deposition ice nucleation}

The concept that is used to capture the ice nucleation efficiency of volcanic ash particle relies on the so-called iceactive surface site density $n_{\mathrm{s}}$ (DeMott, 1995; Connolly et al., 2009). The concept of ice-active surface sites assumes that the time-dependence of the ice nucleation process - which is due to its stochastic nature - can be neglected under certain circumstances and substituted by a singular approach only considering thresholds at which ice nucleation is initiated (Niedermeier et al., 2010). A similar time-independent concept already has been proposed by Vali (1971) who described immersion freezing by an ice nuclei concentration $k(T)$, with $k(T)$ being the concentration of ice nuclei becoming active at a certain temperature. Taking up this idea, Fletcher (1974) then formulated a temperature-dependent expression for the ice nucleation sites per square centimeter of particles being immersed in a droplet.

Using the singular approach instead of a stochastic description of the ice nucleation properties appears to be a reasonably good representation for the ice nucleation efficiencies observed in our experiments while avoiding the introduction of a complex set of parameters which would be needed for a thorough description of the polydisperse aerosol

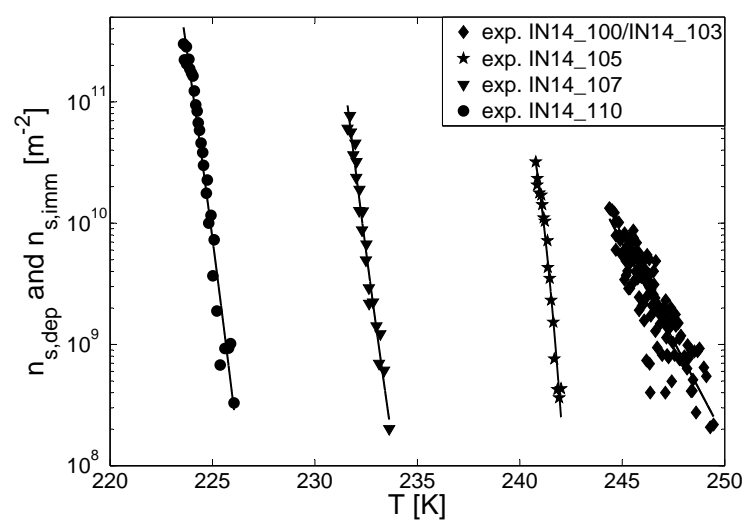

Fig. 7. Relation between temperature and the ice-active surface site densities in deposition nucleation mode $n_{\mathrm{s} \text {, dep }}$ (for three experiments: $\bullet, \mathbf{\nabla}, \star)$ and, for comparison, the ice-active surface site densities in immersion freezing mode $n_{\mathrm{s} \text {,imm }}(\downarrow)$; lines are exponential fits to measured data.

population by a distribution of contact angles (Marcolli et al., 2007). There are also stronger indications that ice crystal concentrations observed in AIDA experiments depend on the temperature (and $\mathrm{RH}_{\text {ice }}$ for deposition nucleation) rather than on time (e.g. Möhler et al., 2006).

For the interpretation of our data, we employed a simplified version of the concept mentioned above (following Niemand et al., 2011) in which the ice-active surface site density (at a certain temperature and for deposition nucleation additionally at a certain relative humidity over ice) is defined as the ratio between the number density of ice cystals $n$ green (in $\mathrm{cm}^{-3}$ ) and the total aerosol surface density $A$ (in $\mu \mathrm{m}^{2} \mathrm{~cm}^{-3}$ ) as estimated from the lognormal fits to the SMPS/APS measurements

$n_{\mathrm{s}}=\frac{n}{A}$.

Equation 1 is a linear approximation for the exponential function which is commonly used (e.g. Connolly et al., 2009, Murray et al., 2011). This approximation can be used for small activated fractions $(f<10 \%)$. For the calculation of $n_{\mathrm{s}}$ it has been taken into account that the aerosol surface density $A$ decreases in the course of an expansion experiment because the aerosol is diluted by pumping the AIDA chamber. Since $n_{\mathrm{S}}$ is calculated for the total aerosol surface density $A, n_{\mathrm{s}}$ must be interpreted as an average over all particle sizes, not taking into account that chemical composition and thus ice-active surface site densities might vary among different particle size classes. Note that $A$ being estimated from the fits to the SMPS/APS measurements - under the assumption of spherical particles - can be considered as a lower limit for the accessible surface area of the volcanic ash particles which are highly non-spherical.

Immersion freezing and deposition nucleation are treated separately, since ice-active surface site densities depend on 


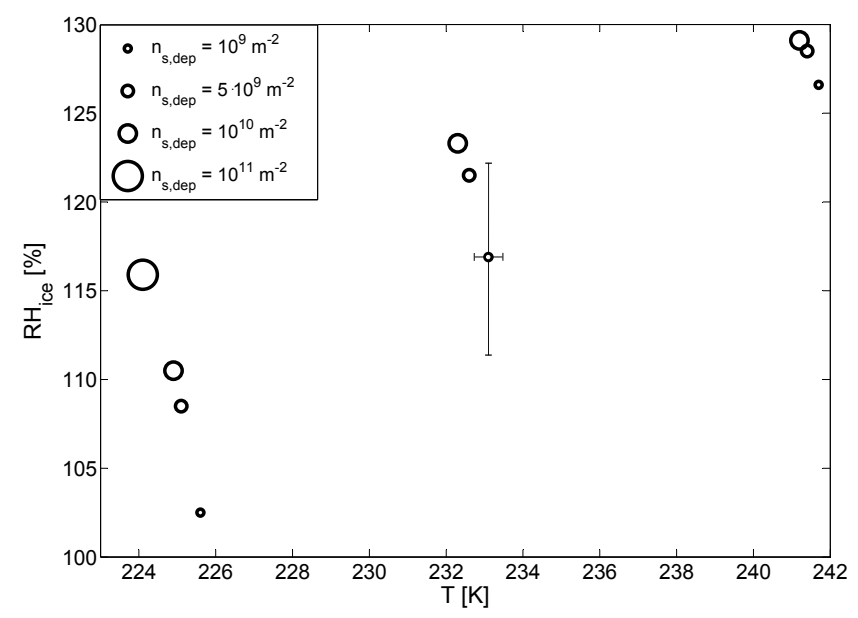

Fig. 8. Ice-active surface site densities for deposition nucleation $n_{\mathrm{s} \text {, dep }}$ of volcanic ash particles (size of circles indicates value of $n_{\mathrm{s}, \mathrm{dep}}$ ) with respect to relative humidity over ice and temperature.

temperature and relative humidity over ice for deposition nucleation, whereas for immersion freezing, temperature alone is the determining factor. In the case of immersion freezing, the aerosol surface density $A$ refers to all particles activated to droplets. Since in our experiments nearly all aerosol particles were activated to droplets before freezing was initiated, $A$ is estimated to equal the total aerosol surface as derived from APS/SMPS measurements.

First, the results for immersion freezing are discussed, followed by a presentation of ice-active surface site densities for deposition nucleation. Figure 6 depicts the ice-active surface site densities derived from two experiments (IN14_100 and IN14_103). Both expansion experiments started at the same temperature, but during the second experiment (IN14_103) a cyclone was operated in series with the rotating brush generator, which resulted in the elimination of particles larger than approximately $5 \mu \mathrm{m}$ (see Fig. 3). Since freezing occured after aerosol particles had been activated to droplets, Fig. 6 represents ice-active surface site densities for immersion freezing of volcanic ash particles. For both experiments, total aerosol surface values were relatively similar with 385 and $400 \mu \mathrm{m}^{2} \mathrm{~cm}^{-3}$, respectively, and also the measured ice crystal number densities did not differ much. The overlap between both experiments demonstrates that ice-active surface site densities $n_{\mathrm{s} \text {,imm }}$ are similar within uncertainties from measurements and fitting procedures. Thus, it can be concluded that larger particles within the size interval between 5 and $10 \mu \mathrm{m}$ - constituting roughly half of the total aerosol surface - do not contribute over-proportionally to the ice-active surface site density $n_{\mathrm{s} \text {,imm }}$ in comparison to the particles smaller than $5 \mu \mathrm{m}$. The assumption of $n_{\mathrm{s}, \mathrm{imm}}$ not depending strongly on particle size is therefore supported by the aforementioned finding. From the measurement data, a fit relating the ice-active surface site density $n_{\mathrm{s}, \mathrm{imm}}$ in immersion freezing mode and temperature was derived (method described in detail by Niemand et al., 2011):

$n_{\mathrm{s}, \mathrm{imm}}(T)=\frac{n_{\mathrm{imm}}}{A}=\exp (-0.74 \times T+203.77) \mathrm{m}^{-2}$

where $T$ is temperature in $(\mathrm{K}), n_{\mathrm{imm}}$ the ice crystal number density and $A$ the aerosol surface density scaled with losses due to diluting the aerosol by pumping. This relation is valid for temperatures between 244 and $250 \mathrm{~K}$. Since above $250 \mathrm{~K}$ the ice fraction $f$ was less than $0.1 \%$, for $n_{\mathrm{s}, \text { imm }}$ only a rough estimate of $\sim 10^{8} \mathrm{~m}^{-2}$ at $252 \mathrm{~K}$ can be given. The dashed lines in Fig. 6 depict the uncertainty $\Delta n_{\mathrm{s} \text {,imm }}$ of the fit that can be attributed to measurement and evaluation uncertainties in the ice crystal number density $n_{\text {imm }}$ (as derived from the WELAS/WELAS2 measurements) and the aerosol surface density $A$ (as derived from the APS/SMPS measurements). From the measurement uncertainties $\Delta n$ and $\Delta A$ being at least $\pm 25 \%, \Delta n_{\mathrm{s} \text {,imm }}$ is estimated to be $\pm 35 \%$ of $n_{\mathrm{s}, \mathrm{imm}}$.

Note that a factor that could have a major influence on the measurement uncertainty $\Delta A$ is that $A$ is derived under the simplifying assumption of spherical particles which does not apply for volcanic ash particles. However, also in volcanic ash dispersion models (Emeis et al., 2011) and for the evaluation of atmospheric measurements (Stohl et al., 2011) volcanic ash particles are assumed to be spherical.

Compared to our observations, the ice-active surface site densities for Asian and Saharan dust in immersion freezing mode are larger with $\sim 10^{11} \mathrm{~m}^{-2}$ at a temperature of $250 \mathrm{~K}$ (Connolly et al., 2009), but overall we find that, with regard to the initiation of immersion freezing, volcanic ash is nearly as efficient as other natural mineral dusts. Its efficiency is comparable to Canary Dust, which has been investigated during an extensive study of the ice nucleation properties of several mineral dusts (Niemand et al., 2011). The ice nucleation properties of kaolinite particles have been investigated with a cold stage setup in a study by Murray et al. (2011) and significantly lower ice-active surface densities with $n_{\mathrm{s}} \sim 10^{7} \mathrm{~m}^{-2}$ were found at $245 \mathrm{~K}$.

Analogously, the ice-active surface site densities have been calculated for deposition nucleation at temperatures below $242 \mathrm{~K}$. In Fig. 8 ice-active surface site densities are presented as a function of temperature and relative humidity over ice. The data points shown in Fig. 8 are derived from separately analysing the relation between ice-active surface site densities and each factor, namely temperature and relative humidity over ice, for the experiments IN14_105, IN14_107, and IN14_110. The uncertainties of temperature $T$ and relative humidity over ice $\mathrm{RH}_{\text {ice }}$ result both from the measurement uncertainties of those two variables and from the analysis that is described below. Uncertainties are estimated to be $\Delta T= \pm 0.3 \mathrm{~K}$ and $\Delta \mathrm{RH}_{\text {ice }}= \pm 5 \%$.

The relation between temperature and ice-active surface site densities for both ice nucleation modes is shown in Fig. 7 as an example. The black lines in Fig. 7 result from 
fitting temperature-dependent exponential functions to each of the $n_{\mathrm{s}}$-trajectories. The difference between experiments in which immersion freezing occured (IN14_100 and IN14_103 - see Table 1 for reference) is clearly visible in contrast to those experiments where deposition nucleation was observed (IN14_105, IN14_107 and IN14_110). First, it can be seen from Fig. 7 that the highest values for ice-active surface site densities are observed in deposition nucleation mode at low temperatures: for the maximum values of supersaturation over ice that were reached during our experiments, $n_{\mathrm{s} \text {, dep }}$ is as large as $10^{11} \mathrm{~m}^{-2}$, whereas for immersion freezing iceactive surface site densities that we observed hardly exceed $10^{10} \mathrm{~m}^{-2}$. The second difference between both ice nucleation modes is that the slope with respect to temperature is apparently much steeper for ice nucleation in deposition mode than for immersion freezing. This behaviour results from the fact that the ice-active surface site density $n_{\mathrm{s}, \mathrm{imm}}(T)$ solely depends on temperature, whereas for deposition nucleation $n_{\mathrm{s} \text {, dep }}\left(\mathrm{RH}_{\mathrm{ice}}, T\right)$ depends on relative humidity over ice $\mathrm{RH}_{\text {ice }}(T)$ and temperature $T$. Taking into account the implicit dependence of $n_{\mathrm{s} \text {, dep }}\left(\mathrm{RH}_{\mathrm{ice}}, T\right)$ on temperature with

$\frac{d n_{\mathrm{s}, \mathrm{dep}}}{d T}=\frac{\partial n_{\mathrm{s}, \mathrm{dep}}}{\partial T}+\frac{\partial n_{\mathrm{s}, \mathrm{dep}}}{\partial\left(\mathrm{RH}_{\mathrm{ice}}\right)} \frac{\partial\left(\mathrm{RH}_{\mathrm{ice}}\right)}{\partial T}$

it can be estimated for the $R H_{\text {ice-trajectories observed during }}$ our experiments that the second term of the above equation dominates the temperature dependence. Thus, the steeper slope results from the predominant influence of relative hu-

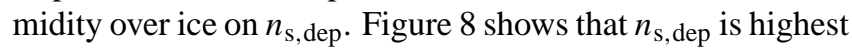
at low temperature and high relative humidity over ice, reaching values of $10^{11} \mathrm{~m}^{-2}$. Also, it can be seen that ice-active surface site densities monotonously increase with decreasing temperature and higher supersaturation over ice.

Note that the data shown in Fig. 7 suggests that experiment IN14_105 belongs to the group of deposition nucleation experiments. However, as there are indications for a contribution via immersion freezing, data points in Fig. 8 above $240 \mathrm{~K}$ represent a combination of deposition nucleation and immersion freezing. During experiment IN14_105 the relative humidity continuously stayed below water saturation which would allow only for deposition freezing. However, the SIMONE depolarisation was observed to drop due to water uptake by volcanic ash particles even before reaching water saturation. Thus, it can be assumed that there was a non-negligible contribution via immersion freezing. Since the contributions of immersion freezing and deposition nucleation to the observed ice crystal concentration could not be quantified exactly, these data points above $240 \mathrm{~K}$ were excluded for the following analysis. A fit to the data below $240 \mathrm{~K}$ gives the following equation:

$$
\begin{aligned}
& n_{\mathrm{s}, \mathrm{dep}}\left(\mathrm{RH}_{\mathrm{ice}}, T\right)=\frac{n_{\text {dep }}}{A} \\
& =10^{9} \times \exp \left(-0.5 \times\left(T-T_{0}\right)+27.0 \times\left(\mathrm{RH}_{\text {ice }}-\mathrm{RH}_{\mathrm{ice}, 0}\right)\right) \mathrm{m}^{-2}
\end{aligned}
$$

with $\mathrm{RH}_{\text {ice }, 0}=102.5 \%$ and $T_{0}=225.6 \mathrm{~K}$. $A$ is again the dilution-scaled aerosol surface and $n_{\text {dep }}$ the number density of ice crystals produced by deposition nucleation. For temperatures between 224 and $234 \mathrm{~K}$ and relative humidities over ice between 102 and $123 \%$, this relation predicts iceactive surface site densities in deposition nucleation mode with a precision of $\pm 20 \%$.

From data presented in former deposition nucleation studies (Möhler et al., 2006) estimates for the ice-active surface site densities of ATD (Arizona Test Dust, Powder Technology Inc.), Asian Dust and Saharan Dust can be calculated. Those calculations yield ice-active surface site densities $n_{\text {s, dep }} \sim 10^{10} \mathrm{~m}^{-2}$ (at $T \sim 220 \mathrm{~K}$ and $\mathrm{RH}_{\text {ice }} \sim 130 \%$ ) for Asian Dust and Saharan Dust. For ATD ice-active-surface site densities are larger with $n_{\mathrm{s} \text {, dep }} \sim 10^{11} \mathrm{~m}^{-2}$ at a higher temperature $(T=223 \mathrm{~K})$ and lower relative humidity over ice $\left(\mathrm{RH}_{\mathrm{ice}} \sim 105 \%\right)$. Note that ATD consists of Arizonian sand that has been milled, washed, dried and sieved in several steps, whereas Asian Dust and Saharan Dust have only been sieved but not processed otherwise. From comparing our measurement results to the aforementioned estimates, it can be concluded that initiation of deposition nucleation by volcanic ash is less efficient than with ATD. In contrast, volcanic ash particles appear to be more efficient ice nuclei in deposition nucleation mode than Asian and Saharan Dust.

Ice-active surface site densities derived from atmospheric ice nuclei measurements investigating the contribution of volcanic ash are only available for warmer temperatures $(\sim 255 \mathrm{~K})$ and find $n_{\mathrm{s}, \mathrm{dep}}=2 \times 10^{9} \mathrm{~m}^{-2}$ (Bingemer et al., 2011). At this temperature, we have not observed any ice nucleation.

\section{Conclusions}

Volcanic ash particles are able to nucleate ice over a large range of atmospheric conditions with regard to relative humidity and temperature. Our results agree well with a study of Hoyle et al. (2011) in which the ice nucleation properties of the same Eyjafjallajökull sample are investigated, finding that volcanic ash particles induce ice nucleation over a temperature range between 263 and $223 \mathrm{~K}$. In our experiments, immersion freezing is observed at temperatures below $252 \mathrm{~K}$. However, ice-fractions did not exceed a threshold of $0.1 \%$ before reaching temperatures lower than $250 \mathrm{~K}$. Deposition nucleation was observed only at temperatures below $242 \mathrm{~K}$. In our experiments the maximum ice fraction for volcanic ash is about $40 \%$ for deposition nucleation at $\mathrm{RH}_{\text {ice }}=117 \%$ and $T=223 \mathrm{~K}$. Single-particle studies with volcanic ash have found freezing onsets at higher temperatures (Durant et al., 2008; Fornea et al., 2009), but - in contrast to our measurements - volcanic ash particles were larger than $100 \mu \mathrm{m}$ which makes it difficult to directly compare these studies to our measurements where particles were generally smaller than $\sim 10 \mu \mathrm{m}$. These large particles can be assumed to have 
increased freezing probabilities at higher temperatures due to the larger available ice nucleus surface.

With respect to the ice nucleation efficiency of volcanic ash particles, we find ice-active site densities $n_{\text {s,imm }}$ between $10^{8} \mathrm{~m}^{-2}$ and $10^{10} \mathrm{~m}^{-2}$ for a temperature range between 250 and $244 \mathrm{~K}$ for ice nucleation via the immersion freezing mode. For deposition nucleation, $n_{\mathrm{s}, \mathrm{dep}}$ is approximately two orders of magnitude larger with $10^{11} \mathrm{~m}^{-2}$ at $224 \mathrm{~K}$ and $\mathrm{RH}_{\text {ice }}=116 \%$. Thus, fine volcanic ash from the Eyjafjallajökull eruption in April 2010 is at least as efficient as certain natural mineral dusts both in immersion freezing and deposition nucleation mode (Field et al., 2006; Niemand et al., 2011; Möhler et al., 2006) but initiates deposition nucleation less efficiently than ATD (Connolly et al., 2009). Recent measurements of volcanic ash particles as atmospheric ice nuclei are only available for deposition nucleation and find $n_{\mathrm{s}, \text { dep }}=2 \times 10^{9} \mathrm{~m}^{-2}$ at $255 \mathrm{~K}$ (Bingemer et al., 2011; Möhler et al., 2006). In this temperature regime, we do not find a contribution by deposition nucleation, but only immersion freezing at slightly lower temperatures. Also, at $250 \mathrm{~K}$ iceactive surface site densities measured in our experiments are significantly smaller with $n_{\mathrm{s}, \text { imm }} \sim 10^{8} \mathrm{~m}^{-2}$. For both ice nucleation modes, fits were calculated relating ice-active surface site densities to temperature and, for deposition nucleation, to relative humidity over ice.

Our experimental results have shown similarities between the ice nucleation behaviour of certain mineral dusts and fine volcanic ash from the Eyjafjallajökull. Since estimates for the atmospheric fluxes of fine volcanic ash suggest an amount of 176-256 Tg per year (Durant et al., 2010), volcanic ash particles being efficient ice nuclei are likely to have a nonnegligible influence on atmospheric processes which should be investigated further. However, volcanic ash ice nuclei are currently neglected in global climate models (e.g. Hoose et al., 2010). From atmospheric size distribution measurements in the Eyjafjallajökull ash plume (Schumann et al., 2011), estimates for atmospheric ice nuclei concentrations can be derived from the aerosol surface distributions and the ice-active surface site density at a certain temperature: for immersion freezing at $248 \mathrm{~K}$, roughly a concentration between 30 and $150 \mathrm{IN} / 1$ can be calculated with the aerosol surfaces $\left(A_{\mathrm{L}} \approx 30 \mu \mathrm{m}^{2} \mathrm{~cm}^{-3}\right.$ and $\left.A_{\mathrm{NA}} \approx 150 \mu \mathrm{m}^{2} \mathrm{~cm}^{-3}\right)$ taken from Fig. 7 in Schumann et al. (2011) in which aerosol surface distributions from two measurements over Leipzig (19 April) and the North Atlantic (2 May) are depicted.

Open questions such as the influence of partial coatings with sulphuric acid on ice nucleation properties require further investigation and could be adressed as a part of a comparison between different volcanic ash samples. Future experiments could also give hints to the relation between ice nucleation properties of volcanic ash and different volcanic eruption types.
Acknowledgements. Gudrun Larsen (Institute of Earth Sciences, University of Iceland) is thanked for kindly having provided the volcanic ash sample from Eyjafjallajökull. Support by the AIDA technician team is gratefully acknowledged.

We acknowledge support by Deutsche Forschungsgemeinschaft and Open Access Publishing Fund of Karlsruhe Institute of Technology. Part of this research was funded by the Helmholtz Association through the President's Initiative and Networking Fund.

Edited by: W. Birmili

\section{References}

Bingemer, H., Klein, H., Ebert, M., Haunold, W., Bundke, U., Herrmann, T., Kandler, K., Müller-Ebert, D., Weinbruch, S., Judt, A., Ardon-Dryer, K., Levin, Z., and Curtius, J.: Atmospheric ice nuclei in the Eyjafjallajökull volcanic ash plume, Atmos. Chem. Phys. Discuss., 11, 2733-2748, doi:10.5194/acpd11-2733-2011, 2011.

Cantrell, W. and Heymsfield, A.: Production of Ice in Tropospheric Clouds: A Review, B. Am. Meteorol. Soc., 86, 795-807, doi:10.1175/BAMS-86-6-795, 2005.

Connolly, P. J., Möhler, O., Field, P. R., Saathoff, H., Burgess, R., Choularton, T., and Gallagher, M.: Studies of heterogeneous freezing by three different desert dust samples, Atmos. Chem. Phys., 9, 2805-2824, doi:10.5194/acp-9-2805-2009, 2009.

Cooper, W. A.: A Possible Mechanism for Contact Nucleation, J. Atmos. Sci., 31, 1832-1837, doi:10.1175/15200469(1974)031;1832:APMFCN ¿2.0.CO;2, 1974.

DeMott, P. J.: Quantitative descriptions of ice formation mechanisms of silver iodide-type aerosols, Atmos. Res., 38, 63-99, doi:10.1016/0169-8095(94)00088-U, 1995.

Durant, A. J., Shaw, R. A., Rose, W. I., Mi, Y., and Ernst, G. G. J.: Ice nucleation and overseeding of ice in volcanic clouds, J. Geophys. Res., 113, D09206, doi:10.1029/2007JD009064, 2008.

Durant, A. J., Bonadonna, C., and Horwell, C. J.: Atmospheric and Environmental Impacts of Volcanic Particles, Elements, 6, 235240, doi:10.2113/gselements.6.4.235, 2010.

Eiríksdottir, E. and Alfredsson, H.: Leaching experiment on ash from Eyjafjallajökull, available at: http://www.earthice.hi. is/page/IES-EY-CEMCOM (last access: 16 December 2011), 2010.

Emeis, S., Forkel, R., Junkermann, W., Schäfer, K., Flentje, H., Gilge, S., Fricke, W., Wiegner, M., Freudenthaler, V., Groß, S., Ries, L., Meinhardt, F., Birmili, W., Münkel, C., Obleitner, F., and Suppan, P.: Measurement and simulation of the 16/17 April 2010 Eyjafjallajökull volcanic ash layer dispersion in the northern Alpine region, Atmos. Chem. Phys., 11, 2689-2701, doi:10.5194/acp-11-2689-2011, 2011.

Fahey, D. W., Gao, R. S., and Möhler, O.: Summary of the AquaVIT Water Vapor Intercomparison: Static Experiments, available at: https://aquavit.icg.kfa-juelich.de/WhitePaper (last access: 16 December 2011), 2009.

Field, P. R., Möhler, O., Connolly, P., Krämer, M., Cotton, R., Heymsfield, A. J., Saathoff, H., and Schnaiter, M.: Some ice nucleation characteristics of Asian and Saharan desert dust, Atmos. Chem. Phys., 6, 2991-3006, doi:10.5194/acp-6-2991-2006, 2006. 
Flentje, H., Claude, H., Elste, T., Gilge, S., Köhler, U., PlassDülmer, C., Steinbrecht, W., Thomas, W., Werner, A., and Fricke, W.: The Eyjafjallajökull eruption in April 2010 - detection of volcanic plume using in-situ measurements, ozone sondes and lidar-ceilometer profiles, Atmos. Chem. Phys., 10, 1008510092, doi:10.5194/acp-10-10085-2010, 2010.

Fletcher, A. N.: Temperature Dependence of the Active Site Concentration of Ice Nucleants, J. Atmos. Sci., 31, 1718-1720, 1974.

Fletcher, N. H.: Active Sites and Ice Crystal Nucleation, J. Atmos. Sci., 26, 1266-1271, doi:10.1175/15200469(1969)026;1266:ASAICN i2.0.CO;2, 1969.

Formenti, P., Elbert, W., Maenhaut, W., Haywood, J., and Andreae, M. O.: Chemical composition of mineral dust aerosol during the Saharan Dust Experiment (SHADE) airborne campaign in the Cape Verde region, September 2000, J. Geophys. Res., 108, 8576, doi:10.1029/2002JD002648, 2003.

Fornea, A. P., Brooks, S. D., Dooley, J. B., and Saha, A.: Heterogeneous freezing of ice on atmospheric aerosols containing ash, soot, and soil, J. Geophys. Res., 114, D13201, doi:10.1029/2009JD011958, 2009.

Gislason, S. R., Hassenkam, T., Nedel, S., Bovet, N., Eiriksdottir, E. S., Alfredsson, H. A., Hem, C. P., Balogh, Z. I., Dideriksen, K., Oskarsson, N., Sigfusson, B., Larsen, G., and Stipp, S. L. S.: Characterization of Eyjafjallajökull volcanic ash particles and a protocol for rapid risk assessment, Proc. Nat. Aca. Sci., 108, 7307-7312, doi:10.1073/pnas.1015053108, 2011.

Gudmundsson, M. T., Pedersen, R., Vogfjörd, K., Thorbjarnardóttir, B., Jakobsdóttir, S., and Roberts, M. J.: Eruptions of Eyjafjallajökull Volcano, Iceland, Eos Trans. AGU, 91, 190-191, 2010.

Hobbs, P. V., Fullerton, C. M., and Bluhm, G. C.: Ice Nucleus Storms in Hawaii, Nature, 230, 90-91, doi:10.1038/physci230090a0, 1971.

Hoose, C., Kristjánsson, J. E., Chen, J.-P., and Hazra, A.: A Classical-Theory-Based Parameterization of Heterogeneous Ice Nucleation by Mineral Dust, Soot, and Biological Particles in a Global Climate Model, J. Atmos. Sci., 67, 2483-2503, doi:10.1175/2010JAS3425.1, 2010.

Hoyle, C. R., Pinti, V., Welti, A., Zobrist, B., Marcolli, C., Luo, B., Höskuldsson, Á., Mattsson, H. B., Stetzer, O., Thorsteinsson, T., Larsen, G., and Peter, T.: Ice nucleation properties of volcanic ash from Eyjafjallajökull, Atmos. Chem. Phys., 11, 9911-9926, doi:10.5194/acp-11-9911-2011, 2011.

Ilyinskaya, E., Tsanev, V., Martin, R., Oppenheimer, C., Blond, J. L., Sawyer, G., and Gudmundsson, M.: Near-source observations of aerosol size distributions in the eruptive plumes from Eyjafjallajökull volcano, March-April 2010, Atmos. Environ., 45, 3210-3216, doi:10.1016/j.atmosenv.2011.03.017, 2011.

Isono, K., Komabayasi, M., and Ono, A.: The Nature and the Origin of Ice Nuclei in the Atmosphere, J. Meteorol. Soc. Jpn., 37, $211-$ 233, 1959a.

Isono, K., Komobayasi, M., and Ono, A.: Volcanoes as a Source of Atmospheric Ice Nuclei, Nature, 183, 317-318, doi:10.1038/183317a0, 1959b.

Krueger, B. J., Grassian, V. H., Cowin, J. P., and Laskin, A.: Heterogeneous chemistry of individual mineral dust particles from different dust source regions: the importance of particle mineralogy, Atmos. Environ., 38, 6253-6261, doi:10.1016/j.atmosenv.2004.07.010, 2004.

Linke, C., Möhler, O., Veres, A., Mohácsi, Á., Bozóki, Z., Szabó,
G., and Schnaiter, M.: Optical properties and mineralogical composition of different Saharan mineral dust samples: a laboratory study, Atmos. Chem. Phys., 6, 3315-3323, doi:10.5194/acp-63315-2006, 2006.

Marcolli, C., Gedamke, S., Peter, T., and Zobrist, B.: Efficiency of immersion mode ice nucleation on surrogates of mineral dust, Atmos. Chem. Phys., 7, 5081-5091, doi:10.5194/acp-7-50812007, 2007.

Mason, B. J. and Maybank, J.: Ice-nucleating properties of some natural mineral dusts, Q. J. R. Meteorol. Soc., 84, 235-241, doi:10.1002/qj.49708436104, 1958.

Mather, T. A., Pyle, D. M., and Oppenheimer, C.: Tropospheric Volcanic Aerosol, Volcanism and the Earth's Atmosphere, Geophys. Monogr., 139, 189-212, doi:10.1029/139GM12, 2003.

Möhler, O., Field, P. R., Connolly, P., Benz, S., Saathoff, H., Schnaiter, M., Wagner, R., Cotton, R., Krämer, M., Mangold, A., and Heymsfield, A. J.: Efficiency of the deposition mode ice nucleation on mineral dust particles, Atmos. Chem. Phys., 6, 3007-3021, doi:10.5194/acp-6-3007-2006, 2006.

Möhler, O., Benz, S., Saathoff, H., Schnaiter, M., Wagner, R., Schneider, J., Walter, S., Ebert, V., and Wagner, S.: The effect of organic coating on the heterogeneous ice nucleation efficiency of mineral dust aerosols, Environ. Res. Lett.s, 3, 025007, doi:10.1088/1478-9326/3/2/025007, 2008.

Murphy, D. M. and Koop, T.: Review of the vapour pressures of ice and supercooled water for atmospheric applications, Q. J. R. Meteorol. Soc., 131, 1539-1565, doi:10.1256/qj.04.94, 2005.

Murray, B. J., Broadley, S. L., Wilson, T. W., Atkinson, J. D., and Wills, R. H.: Heterogeneous freezing of water droplets containing kaolinite particles, Atmos. Chem. Phys., 11, 4191-4207, doi:10.5194/acp-11-4191-2011, 2011.

Niedermeier, D., Hartmann, S., Shaw, R. A., Covert, D., Mentel, T. F., Schneider, J., Poulain, L., Reitz, P., Spindler, C., Clauss, T., Kiselev, A., Hallbauer, E., Wex, H., Mildenberger, K., and Stratmann, F.: Heterogeneous freezing of droplets with immersed mineral dust particles - measurements and parameterization, Atmos. Chem. Phys., 10, 3601-3614, doi:10.5194/acp-10-36012010, 2010.

Niemand, M., Möhler, M., Vogel, B., Vogel, H., Hoose, C., Connolly, P., Klein, H., Bingemer, H., DeMott, P., Skrotzki, J., and Leisner, T.: Parameterization of immersion freezing on mineral dust particles: An application in a regional scale model, submitted, 2011.

Pruppacher, H. R. and Klett, J. D.: Microphysics of clouds and precipitation, Atmospheric and oceanographic sciences library; 18, Kluwer, Dordrecht, 2nd rev. and enl. Edn., 1997.

Raga, G. B., Kok, G. L., Baumgardner, D., Báez, A., and Rosas, I.: Evidence for volcanic influence on Mexico City aerosols, Geophys. Res. Lett., 26, 1149-1152, doi:10.1029/1999GL900154, 1999.

Rose, W. I. and Durant, A. J.: Fine ash content of explosive eruptions, J. Volcanol. Geoth. Res, 186, 32-39, doi:10.1016/j.jvolgeores.2009.01.010, 2009.

Schaefer, V. J.: The Formation of Ice Crystals in the Laboratory and the Atmosphere, Chem. Rev., 44, 291-320, doi:10.1021/cr60138a004, 1949.

Schnell, R. C. and Delany, A.: Airborne ice nuclei near an active volcano, Nature, 264, 535-536, doi:10.1038/264535a0, 1976.

Schumann, U., Weinzierl, B., Reitebuch, O., Schlager, H., Minikin, 
A., Forster, C., Baumann, R., Sailer, T., Graf, K., Mannstein, H., Voigt, C., Rahm, S., Simmet, R., Scheibe, M., Lichtenstern, M., Stock, P., Rüba, H., Schäuble, D., Tafferner, A., Rautenhaus, M., Gerz, T., Ziereis, H., Krautstrunk, M., Mallaun, C., Gayet, J.-F., Lieke, K., Kandler, K., Ebert, M., Weinbruch, S., Stohl, A., Gasteiger, J., Groß, S., Freudenthaler, V., Wiegner, M., Ansmann, A., Tesche, M., Olafsson, H., and Sturm, K.: Airborne observations of the Eyjafjalla volcano ash cloud over Europe during air space closure in April and May 2010, Atmos. Chem. Phys., 11, 2245-2279, doi:10.5194/acp-11-2245-2011, 2011.

Seifert, P., Ansmann, A., Groß, S., Freudenthaler, V., Heinold, B., Hiebsch, A., Mattis, I., Schmidt, J., Schnell, F., Tesche, M., Wandinger, U., and Wiegner, M.: Ice formation in ashinfluenced clouds after the eruption of the Eyjafjallajökull volcano in April 2010, J. Geophys. Res., 116, D00U04, doi:10.1029/2011JD015702, 2011.

Shaw, R. A., Durant, A. J., and Mi, Y.: Heterogeneous Surface Crystallization Observed in Undercooled Water, J. Phys. Chem. B, 109, 9865-9868, doi:10.1021/jp0506336, 2005.
Soden, B. J., Wetherald, R. T., Stenchikov, G. L., and Robock, A.: Global Cooling After the Eruption of Mount Pinatubo: A Test of Climate Feedback by Water Vapor, Science, 296, 727-730, doi:10.1126/science.296.5568.727, 2002.

Stohl, A., Prata, A. J., Eckhardt, S., Clarisse, L., Durant, A., Henne, S., Kristiansen, N. I., Minikin, A., Schumann, U., Seibert, P., Stebel, K., Thomas, H. E., Thorsteinsson, T., Tørseth, K., and Weinzierl, B.: Determination of time- and height-resolved volcanic ash emissions and their use for quantitative ash dispersion modeling: the 2010 Eyjafjallajökull eruption, Atmos. Chem. Phys., 11, 4333-4351, doi:10.5194/acp-11-4333-2011, 2011.

Vali, G.: Quantitative Evaluation of Experimental Results on the Heterogeneous Freezing Nucleation of Supercooled Liquids, J. Atmos. Sci., 28, 402-409, doi:10.1175/15200469(1971)028;0402:QEOERA i2.0.CO;2, 1971.

Vali, G.: Nucleation Terminology, J. Aerosol Sci., 16, 575-576, 1985.

Wagner, R., Linke, C., Naumann, K.-H., Schnaiter, M., Vragel, M., Gangl, M., and Horvath, H.: A review of optical measurements at the aerosol and cloud chamber AIDA, J. Quant. Spectr. Rad. T., 110, 930-949, doi:10.1016/j.jqsrt.2009.01.026, 2009. 